\title{
Risk factors for dysphagia after a spinal cord injury: a systematic review and meta-analysis
}

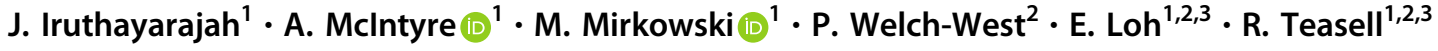

Received: 30 December 2017 / Revised: 7 June 2018 / Accepted: 7 June 2018 / Published online: 28 June 2018

(c) International Spinal Cord Society 2018

\begin{abstract}
Study design Systematic review and meta-analysis.

Objective To determine the risk factors predictive of dysphagia after a spinal cord injury (SCI).

Setting None.

Methods A comprehensive literature search was performed in five scientific databases for English articles that identified risk factors for dysphagia after a SCI in adult ( $\geq 19$ years) individuals. Data extracted included: author name, year and country of publication, participant demographics, sample size, study design, method of dysphagia diagnosis, and risk factor percentages. Methodological quality of studies was assessed using the Newcastle-Ottawa Scale. For identified risk factors, risk percentages were transformed into risk ratios (RR) with $95 \%$ confidence intervals. Quantitative synthesis was performed for risk factors reported in two or more studies using restricted maximum-likelihood estimator random effects models.

Results Eleven studies met inclusion criteria of which ten studies were of moderate quality $(n=10)$. Significant risk factors included: age, injury severity, level of injury, presence of tracheostomy, coughing, voice quality, bronchoscopy need, pneumonia, mechanical ventilation, nasogastric tubes, comorbid injury, and a cervical surgery. Results of the quantitative synthesis indicated that the presence of a tracheostomy posed a threefold greater risk of the development of dysphagia (RR: 3.67); while, cervical surgery posed a 1.3 times greater risk of the development of dysphagia (RR: 1.30).

Conclusions Knowledge of these risk factors can be a resource for clinicians in the early diagnosis and appropriate medical management of dysphagia post SCI.
\end{abstract}

\section{Introduction}

Dysphagia is a disorder of swallowing function, characterized by abnormal movement of a food bolus or liquids from the oral cavity to the esophagus [1,2]. Deglutition, or swallowing, is comprised of a complex series of sequential

Electronic supplementary material The online version of this article (https://doi.org/10.1038/s41393-018-0170-3) contains supplementary material, which is available to authorized users.

J. Iruthayarajah

Jerome.Iruthayarajah@sjhc.london.on.ca

1 Lawson Health Research Institute, Parkwood Institute, London, ON, Canada

2 Parkwood Institute, St. Joseph's Health Care London, London, ON, Canada

3 Schulich School of Medicine \& Dentistry, University of Western Ontario, London, ON, Canada voluntary and involuntary movements occurring in four phases: the oral preparatory, oral, pharyngeal, and esophageal phases $[3,4]$. Dysphagia can take place during any of these phases of swallowing [5]. Swallowing is regulated by the cerebral cortex, brainstem, cranial nerves, and the uppermost levels of the cervical spinal cord, and involves numerous muscle groups $[3,6,7]$. As such, the etiology and presentation of dysphagia can be varied; swallowing dysfunction may arise due to any condition that interferes with the anatomical structures comprising the aerodigestive tract, or their neuronal control and coordination [1, 3, 8].

Dysphagia occurs in a variety of clinical populations, such as stroke and Parkinson's disease [9]. In spinal cord injury (SCI), dysphagia has been identified as a serious problem associated with cervical SCI, occurring in up to $41 \%$ of patients between the acute care period and admission to inpatient rehabilitation [10-14]. However, reported incidence rates of dysphagia vary considerably, and are estimated to be higher during the acute phase of SCI [1, 14]. Typically, the oral or pharyngeal phases of swallowing, or 
both, are affected [10], with variability in severity of swallowing dysfunction [1]. Dysphagia may also develop due to medical interventions required in high-level injuries, such as a tracheostomy, halo orthosis, or cervical spine surgery [14].

Complications secondary to dysphagia within the SCI population include pulmonary sequelae such as transient hypoxemia, atelectasis, chemical pneumonitis, mechanical airway obstruction, bronchospasm, and pneumonia [11]. Furthermore, dysphagia is a predisposing condition for aspiration $[10,15]$, which may contribute to the development of pneumonia and lead to death [3]. Importantly, complications associated with respiration are considered to be leading causes of morbidity and mortality among individuals with SCI [16]. Dysphagia may also lead to malnourishment, compromised ability to communicate, and diminished quality of life $[1,10]$. Despite being associated with significant morbidity, dysphagia remains underrecognized in SCI $[12,15]$.

Early identification of individuals who are at-risk for dysphagia may prevent or reduce the development of associated harmful complications, by facilitating timely diagnosis and treatment [11, 15]. Furthermore, an understanding of risk factors for dysphagia may assist with appropriate treatment planning for tetraplegic patients such that the need for interventions which contribute to or reinforce dysphagia can be modified or reassessed [10]. As such, awareness of factors associated with swallowing dysfunction among individuals with SCI is crucial and has important implications for medical management.

To date, there has been no systematic review which comprehensively summarizes the state of the evidence regarding risk factors for dysphagia in persons with SCI, to better guide clinical practice. The objective of this systematic review and meta-analysis was to identify and quantify the magnitude of published risk factors predictive of dysphagia in SCI.

\section{Methods}

This systematic review and meta-analysis was reported following the guidelines set out in the Preferred Reporting Items for Systematic Reviews and Meta-Analyses (PRISMA) statement [17].

\section{Literature search strategy}

A literature search was performed for articles examining risk factors for dysphagia in SCI published from database inception to August 20, 2017 using the following databases: PubMed, Scopus, Web of Science, CINAHL, and EMBASE. Search terms used for each of the databases included combinations of the following: "spinal cord injury" OR "paraplegia" OR "tetraplegia" OR "quadriplegia" OR "spine injury" AND "dysphagia" OR "swallowing disorder" AND "risk factors". Searches were limited to human studies published in the English language. An example of a full search strategy as performed in the PubMed database is provided in Appendix 1.

\section{Selection criteria}

Articles were selected if they met the following four a priori inclusion criteria:

1. Studies retrospectively or prospectively identified risk factors for dysphagia as a primary outcome.

2. The study population was $\geq 50 \%$ SCI.

3. There were $\geq 3$ adult ( $\geq 19$ years) participants.

4. Where dysphagia was suspected, a clinical diagnosis was performed.

\section{Study selection and data extraction}

Articles were screened for eligibility by two reviewers (JI, AMc) according to inclusion criteria, this included both abstract and full text screening. References of retrieved articles were additionally scanned for any missed relevant citations. Data extraction was performed by these same two reviewers and included: author name, year of publication, country of publication, participant demographics (mean age, gender, level and severity of injury, mean time since injury), sample size, study design, method of dysphagia diagnosis, and proportions of SCI participants with or without the presence of an identified risk factor who had dysphagia. Any discrepancies were resolved by a third reviewer (MM).

\section{Methodological and quality assessment}

The methodological quality of non-randomized studies was assessed by two reviewers (JI, AMc) using the modified Newcastle-Ottawa Scale (NOS). The NOS is scored out of a total of 9; NOS scores below 5 are indicative of low methodological quality, scores between 5 and 7 are indicative of moderate methodological quality, and scores $>7$ are indicative of high methodological quality. A recent systematic review on assessment tools for methodological quality recommends use of the NOS for observational studies [18].

\section{Data synthesis and analysis}

The proportions of SCI participants with or without a risk factor, who had dysphagia, were pooled and included in a 
Fig. 1 Study selection process using PRISMA flow diagram

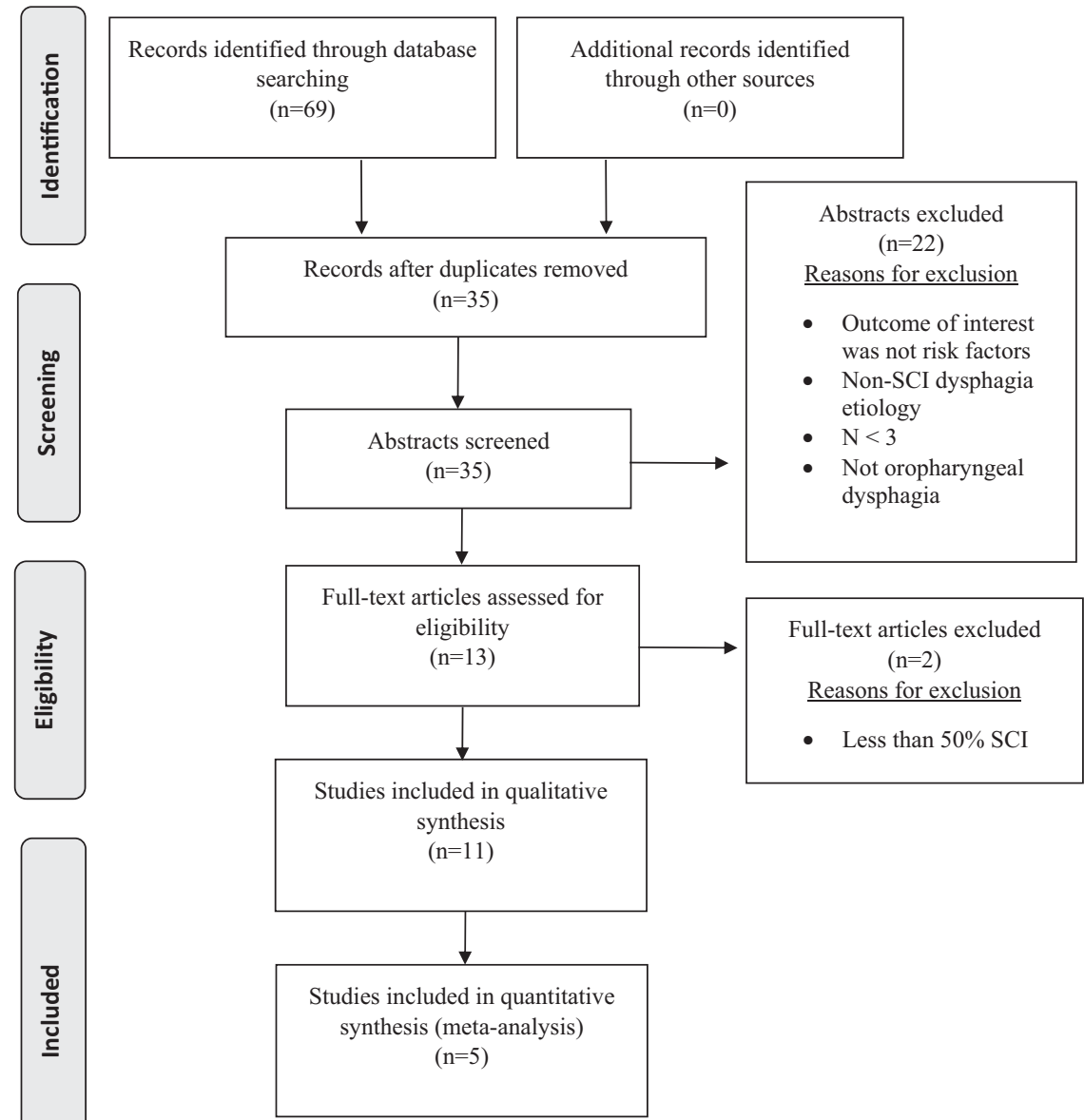

quantitative synthesis when the risk factor was reported by two or more studies. Risk percentages were then transformed into risk ratios (RR) with $95 \%$ confidence intervals using R studio 1.0.143 for each risk factor, including those reported by only one study. Restricted maximum-likelihood estimator random effects models were used for all metaanalyses and calculated using $\mathrm{R}$ studio 1.0.143 using the metafor package. Point estimates are presented as pooled RRs with 95\% confidence intervals. Statistical heterogeneity was evaluated using both Cochran's $Q$ test, and the $I^{2}$ statistic [19]. For the $Q$ test, $p<0.01$ was considered indicative of statistically significant heterogeneity; for the $I^{2}$ statistic, values $>40 \%$ were indicative of moderate to severe heterogeneity [19].

\section{Results}

\section{Study and participant characteristics}

For this systematic review and meta-analysis, 11 of the 69 articles identified from the literature search met inclusion criteria (Fig. 1). Table 1 summarizes the main characteristics of these included studies. Studies were published between 1999 and 2017. The total pooled sample size was 1227 participants with individual study sample sizes ranging from 37 to 298 . The mean age of study participants was $46.8 \pm 9.4$ years, the mean time since injury was $39.1 \pm$ 54.6 days, and all participants had a cervical SCI. Four studies were prospective cohorts $[12,13,15,20]$, and the remaining seven studies were retrospective case-controls or cohorts [10, 11, 21-25]. Six studies reported incidence rates of dysphagia [10-13, 15, 25], with a mean incidence of $30.1 \%$. The method of diagnosis was the bedside swallowing exam (BSE) in six studies [12, 13, 15, 23-25], videofluoroscopy (VFS) in nine studies [10-13, 15, 20, 2224], both BSE and VFS in five [12, 13, 15, 23, 24], fiberoptic endoscopic evaluation of swallowing (FEES) in one [24], and by classification levels of the functional oral intake scale in one [21]. Upon further examination, we noted that four of the included studies are part of the same growing cohort $[12,13,15,23]$. As such, we only used the latest study [15] for calculation of RRs or quantitative synthesis. 
Table 1 Characteristics of included studies

\begin{tabular}{|c|c|c|c|c|c|c|c|}
\hline $\begin{array}{l}\text { First author, ref. } \\
\text { Country } \\
\text { Study design } \\
\text { NOS score }\end{array}$ & $\begin{array}{l}\text { Sample } \\
\text { size } \\
\text { Gender } \\
\text { M: F }\end{array}$ & Mean age & $\begin{array}{l}\text { Level \& } \\
\text { severity of } \\
\text { injury }\end{array}$ & $\begin{array}{l}\text { Mean time } \\
\text { since injury }\end{array}$ & Etiology of SCI & $\begin{array}{l}\text { Method of } \\
\text { dysphagia } \\
\text { diagnosis }\end{array}$ & $\begin{array}{l}\text { Incidence or } \\
\text { prevalence }\end{array}$ \\
\hline $\begin{array}{l}\text { Hayashi et al. [21] } \\
\text { Japan } \\
\text { Case-control } \\
6\end{array}$ & $\begin{array}{l}298 \\
256: 42\end{array}$ & $\begin{array}{l}\text { Median: } 64 \\
\text { yr }\end{array}$ & $\begin{array}{l}\text { Range: C3-C7 } \\
\text { AIS A }(n=98) \\
\text { AIS B }(n=38) \\
\text { AIS C }(n= \\
127) \\
\text { AIS D }(n=35)\end{array}$ & 3 days & Not reported & $\begin{array}{l}\text { Functional oral } \\
\text { intake scale }\end{array}$ & $\begin{array}{l}\text { Prevalence: } \\
7 \%\end{array}$ \\
\hline $\begin{array}{l}\text { Ihalainen et al. } \\
{[20]} \\
\text { Finland } \\
\text { Prospective cohort } \\
6\end{array}$ & $\begin{array}{l}37 \\
31: 6\end{array}$ & $61.2 \mathrm{yr}$ & $\begin{array}{l}\text { C1-C4 }(n= \\
32) \\
\text { C5-C8 }(n=4) \\
\text { AIS A }(n=8) \\
\text { AIS B }(n=3) \\
\text { AIS C }(n=5) \\
\text { AIS D }(n=21)\end{array}$ & 16.4 days & $\begin{array}{l}\text { Sports: } 2 \\
\text { Transport: } 6 \\
\text { Fall: } 28 \\
\text { Unknown: } 1\end{array}$ & VFS & $\begin{array}{l}\text { Prevalence: } \\
51 \%\end{array}$ \\
\hline $\begin{array}{l}\text { Chaw et al. [15] } \\
\text { USA } \\
\text { Prospective cohort } \\
5\end{array}$ & $\begin{array}{l}68 \\
57: 11\end{array}$ & $43 \mathrm{yr}$ & $\begin{array}{l}\text { C1 }(n=2) \\
\text { C2 }(n=6) \\
\text { C3 }(n=14) \\
\text { C4 }(n=27) \\
\text { C5 }(n=10) \\
\text { C6 }(n=4) \\
\text { C7 }(n=3) \\
\text { C8 }(n=2) \\
\text { Severity of } \\
\text { injury not } \\
\text { reported }\end{array}$ & 31.8 days & $\begin{array}{l}\text { MVA: } 22 \\
\text { Fall: } 13 \\
\text { Diving: } 9 \\
\text { Bicycle accident: } 5 \\
\text { GSW } 4 \\
\text { Medical: } 4 \\
\text { Myelopathy: } 4 \\
\text { Other trauma: } 4 \\
\text { Other: } 2\end{array}$ & $\begin{array}{l}\text { BSE } \\
\text { VFS }\end{array}$ & $\begin{array}{l}\text { Incidence: } \\
31 \%\end{array}$ \\
\hline $\begin{array}{l}\text { Shin et al. [22] } \\
\text { Korea } \\
\text { Retrospective } \\
\text { cohort } \\
5\end{array}$ & $\begin{array}{l}121 \\
105: 16\end{array}$ & $44.9 \mathrm{yr}$ & $\begin{array}{l}\text { Range: C1-C8 } \\
\text { AIS A }(n=72) \\
\text { AIS B }(n=20) \\
\text { AIS C }(n=19) \\
\text { AIS D }(n=10)\end{array}$ & 178.4 days & $\begin{array}{l}\text { MVA: } 81 \\
\text { Fall: } 26 \\
\text { Diving: } 4 \\
\text { Other traumatic: } 7 \\
\text { Non-traumatic: } 3\end{array}$ & VFS & $\begin{array}{l}\text { Prevalence: } \\
8 \%\end{array}$ \\
\hline $\begin{array}{l}\text { Seidl et al. [25] } \\
\text { Germany } \\
\text { Retrospective } \\
\text { cohort } \\
5\end{array}$ & $\begin{array}{l}175 \\
144: 31\end{array}$ & $43.5 \mathrm{yr}$ & $\begin{array}{l}\text { C0 }(n=1) \\
\text { C1 }(n=1) \\
\text { C2 }(n=4) \\
\text { C3 }(n=14) \\
\text { C4 }(n=58) \\
\text { C5 }(n=53) \\
\text { C6 }(n=33) \\
\text { C7 }(n=6) \\
\text { C8 }(n=5) \\
\text { Frankel scores: } \\
\text { TA }(n=103) \\
\text { TB }(n=19) \\
\text { TC }(n=21) \\
\text { TD }(n=24) \\
\text { TE }(n=8)\end{array}$ & 56.0 days & $\begin{array}{l}\text { Vertebral fracture: } 136 \\
\text { Spondylodiscitis: } 10 \\
\text { Contusio spinalis: } 10 \\
\text { Tumor: } 5 \\
\text { Spinal stenosis: } 4 \\
\text { Nucleus pulposus } \\
\text { prolaps: } 3 \\
\text { Knife wound: } 1 \\
\text { Postoperative: } 1\end{array}$ & BSE & $\begin{array}{l}\text { Incidence: } \\
16 \%\end{array}$ \\
\hline $\begin{array}{l}\text { Abel et al. [10] } \\
\text { Germany } \\
\text { Retrospective } \\
\text { cohort } \\
4\end{array}$ & $\begin{array}{l}73 \\
51: 22\end{array}$ & $42.9 \mathrm{yr}$ & $\begin{array}{l}\text { Range: } \mathrm{C} 1-\mathrm{C} 7 \\
\text { AIS A }(n=41) \\
\text { AIS B-E }(n= \\
32)\end{array}$ & Not reported & $\begin{array}{l}\text { Trauma: } 56 \\
\text { Spondylitis: } 5 \\
\text { Tumor: } 3 \\
\text { Other: } 9\end{array}$ & VFS & $\begin{array}{l}\text { Prevalence: } \\
34 \%\end{array}$ \\
\hline $\begin{array}{l}\text { Brady et al. [24] } \\
\text { USA } \\
\text { Case-control } \\
6\end{array}$ & $\begin{array}{l}131 \\
\text { Not } \\
\text { reported }\end{array}$ & $55.5 \mathrm{yr}$ & $\begin{array}{l}\text { Range: } \mathrm{C} 1-\mathrm{C} 8 \\
\text { Severity of } \\
\text { injury not } \\
\text { reported }\end{array}$ & Not reported & Not reported & $\begin{array}{l}\text { VFS } \\
\text { BSE } \\
\text { FEES }\end{array}$ & $\begin{array}{l}\text { Prevalence: } \\
55 \%\end{array}$ \\
\hline $\begin{array}{l}\text { Kirshblum et al. } \\
\text { [11] } \\
\text { USA }\end{array}$ & $\begin{array}{l}187 \\
156: 31\end{array}$ & $44.3 \mathrm{yr}$ & $\begin{array}{l}\text { Range: C1-C } 8 \\
\text { AIS A }(n=71) \\
\text { AIS B }(n=5)\end{array}$ & $\begin{array}{l}\text { Median: } \\
30 \text { days }\end{array}$ & $\begin{array}{l}\text { Fall: } 64 \\
\text { MVA: } 65 \\
\text { GSW: } 9\end{array}$ & VFS & $\begin{array}{l}\text { Prevalence: } \\
17 \%\end{array}$ \\
\hline
\end{tabular}


Table 1 (continued)

\begin{tabular}{|c|c|c|c|c|c|c|c|}
\hline $\begin{array}{l}\text { First author, ref. } \\
\text { Country } \\
\text { Study design } \\
\text { NOS score }\end{array}$ & $\begin{array}{l}\text { Sample } \\
\text { size } \\
\text { Gender } \\
\text { M: F }\end{array}$ & Mean age & $\begin{array}{l}\text { Level \& } \\
\text { severity of } \\
\text { injury }\end{array}$ & $\begin{array}{l}\text { Mean time } \\
\text { since injury }\end{array}$ & Etiology of SCI & $\begin{array}{l}\text { Method of } \\
\text { dysphagia } \\
\text { diagnosis }\end{array}$ & $\begin{array}{l}\text { Incidence or } \\
\text { prevalence }\end{array}$ \\
\hline $\begin{array}{l}\text { Case-control } \\
6\end{array}$ & & & $\begin{array}{l}\text { AIS C }(n=59) \\
\text { AIS D }(n=48) \\
\text { AIS E }(n=4)\end{array}$ & & $\begin{array}{l}\text { Diving: } 31 \\
\text { Other: } 18\end{array}$ & & \\
\hline
\end{tabular}

AIS American Spinal Injury Association Impairment Scale, BSE bedside swallowing exam, FEES fiberoptic endoscopic evaluation of swallowing, $G S W$ Gunshot Wound, MVA motor vehicle accident, $V F S$ videofluoroscopy, $Y r$ years

\section{Quality assessment}

Of the 11 included studies, 10 studies were of moderate quality $[11-13,15,20-25]$, and one study was of low quality [10]. Most studies clearly identified the study population, in terms of the comparability of the dysphagia and non-dysphagia cases, and provided adequate statistical analyses. However, in prospective cohort studies, follow-up times were seldom reported, and ascertainment of exposure to a risk factor was not described in case-control studies.

\section{Risk factors for dysphagia}

The following risk factors were identified as being significant predictors of dysphagia and were reported in at least one study: age, injury severity, level of injury, presence of a tracheostomy, coughing, voice quality, bronchoscopy need, pneumonia, mechanical ventilation, nasogastric tubes, comorbid injury, and a cervical surgery. Table 2 reports the RR for each identified factor where risk percentages were available from the studies.

Table 2 Risk ratios with 95\% confidence intervals (CI) for risk factors identified as significant in included studies, ranked from largest to smallest

\begin{tabular}{ll}
\hline Risk factor & Risk ratio (95\% CI) \\
\hline Injury severity [21] & $11.32(2.68-47.72)$ \\
Presence of tracheostomy [11, 15, 21, 22, 24] & $3.67(1.82-7.42)$ \\
Pneumonia [15] & $3.44(1.61-7.37)$ \\
Age $>72$ years [21] & $3.10(1.37-7.02)$ \\
Coughing [20] & $2.67(1.34-5.31)$ \\
Nasogastric tubes [15] & $2.65(1.20-5.86)$ \\
Voice quality [20] & $2.65(1.17-6.01)$ \\
Mechanical ventilation [15] & $2.29(1.11-4.86)$ \\
Bronchoscopy need [20] & $2.11(1.27-3.57)$ \\
Comorbid brain injury [24] & $1.78(1.36-2.33)$ \\
Cervical surgery [11, 24] & \\
\hline
\end{tabular}

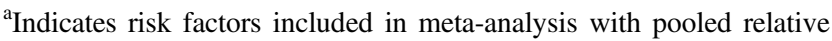
risk ratios

\section{Meta-analyses of risk factors for dysphagia}

The following risk factors were reported by two or more studies and were pooled for meta-analysis.

\section{Presence of a tracheostomy}

Five studies $[11,15,21,22,24]$ were included in the metaanalysis of the presence of a tracheostomy as a risk factor for dysphagia. The presence of a tracheostomy was significantly associated with a threefold greater risk of the development of dysphagia (RR: 3.67 [95\% CI: 1.82-7.42], $p<0.0001$ ) (Fig. 2). Heterogeneity was high across these studies $\left(I^{2}=75.62 \%, Q=30.57\right.$, $\left.(\mathrm{df}=7), p<0.0001\right)$.

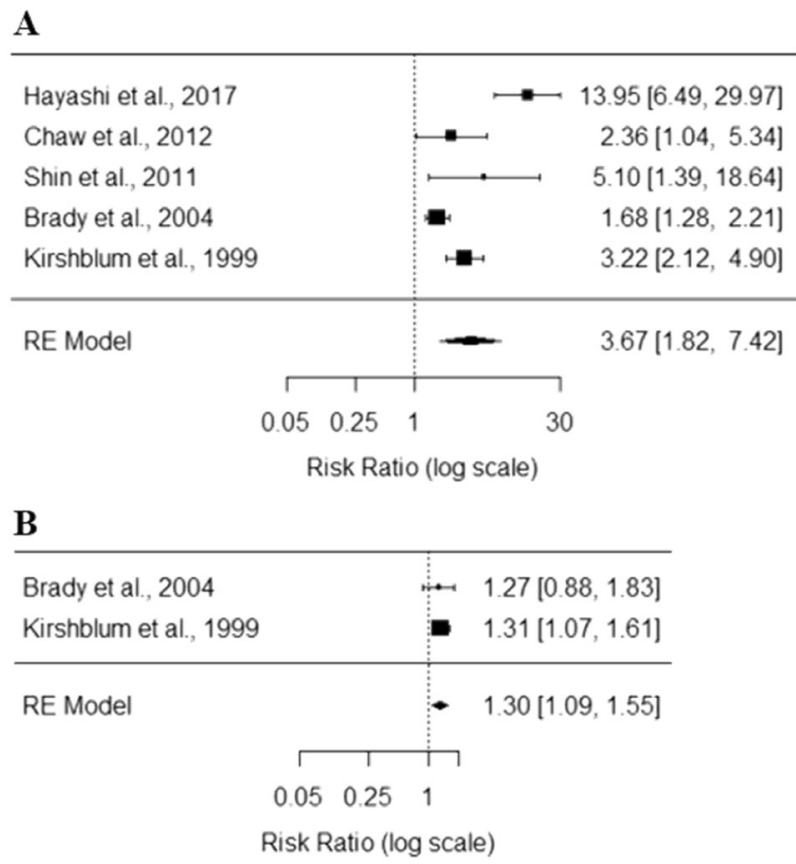

Fig. 2 Forest plot of the association between dysphagia and the following risk factors: a presence of a tracheostomy and $\mathbf{b}$ cervical surgery. Note: The middle vertical line indicates the line of no effect. Squares indicate study RRs, and horizontal lines are the 95\% CI. The diamond at the bottom indicates the pooled RR 


\section{Cervical surgery}

Two studies [11, 24] were included in the meta-analysis of cervical surgery as a risk factor for dysphagia. Cervical surgery was significantly associated with a 1.3 times greater risk of the development of dysphagia (RR: 1.30 [95\% CI: 1.09-1.55], $p=0.0036$ ) (Fig. 2). Heterogeneity was low across these studies $\left(I^{2}=0.00 \%, Q=0.0212,(\mathrm{df}=1), p=\right.$ $0.8841)$.

\section{Discussion}

Dysphagia is an underdiagnosed complication of SCI that is clinically demanding to recognize and treat. Dysphagia can lead to nutritional and pulmonary issues ranging from mild to severe including fear of eating, poor nutrient intake and malnutrition, aspiration, pneumonia, and even choking and death [3]. Additionally, the cost to treat chest complications and the expenses of serial chest imaging arising from aspiration pneumonia when dysphagia is not identified early and properly managed is an important consideration. While dysphagia has been studied extensively in other neurological populations, such as stroke [26], there have been no research syntheses examining this topic in SCI. Given that SCI survivors are a unique population with specialized medical concerns, risk factors identified in other populations may or may not apply clinically. Our study aimed to fill this important gap by specifically identifying risk factors for dysphagia in SCI. Awareness of risk factors for the development of dysphagia in this population can assist in preventing or reducing negative outcomes related to swallowing.

Until this review, the scientific literature has varied in terms of agreed upon risk factors for dysphagia in SCI. Previously, several variables were shown to be both associated and not associated with dysphagia including age [1, 10-13, 20-22, 24, 25], mechanical ventilation [11-13, 15, 23], and level of injury [1, 10, 11, 23, 25]. With the exception of Ihalainen et al. [20], all studies collectively found that tracheostomy was associated with dysphagia. The reasons for differences between studies likely relate to clinical heterogeneity among patients, diagnostic methods for confirming the presence of dysphagia, data collection protocols (i.e., risk factors as a primary versus secondary study outcome), and small sample sizes. To overcome these limitations, the current study systematically searched the research literature for all studies examining risk factors for dysphagia in SCI. Subsequently, for each significant risk factor identified, RRs were calculated with or without pooling proportions from multiple studies, as appropriate for each individual factor. Eleven significant risk factors were identified for which risk percentages were available, and for which RRs were calculated, including: age, injury severity, presence of tracheostomy, coughing, voice quality, bronchoscopy need, pneumonia, mechanical ventilation, nasogastric tubes, comorbid injury, and a cervical surgery. The meta-analyses demonstrated that individuals with the following two risk factors were significantly more likely to develop dysphagia than those without: presence of a tracheostomy $(\mathrm{RR}=3.67, p<0.0001)$, and cervical surgery $(\mathrm{RR}=1.30, p=0.0036)$.

Clinical risk factors (e.g., level, and severity of injury) are associated with dysphagia directly as a result of neuronal injury but may also occur through an association with secondary risk factors such as mechanical ventilation which is required more frequently in severe, high level, and complete SCI [3]. A study of magnetic resonance imaging among those with SCI has shown that prevertebral hyperintensity is negatively correlated with severe paralysis [21, 27]. Thus, swelling of the retropharyngeal space from either vertebral fracture or soft-tissue injury results in swallowing dysfunction [21]. Comorbid injuries, such as brain injury, may also contribute to the development of dysphagia. A dual diagnosis of brain injury has been reported to range from 16 to $74 \%$ of individuals with traumatic SCI [28]. Brain injuries can lead to swallowing dysfunction from a variety of lesion sites that are involved in the neuronal control of swallowing [28]; coupled with SCI, the risk of dysphagia occurrence is potentially higher in comorbid individuals as identified in one study [24] and should be an important consideration for clinicians when screening for dysphagia. Older age was the only demographic risk factor identified in the current study as being related to dysphagia [21]. The physiological changes associated with aging, particularly at the level of the upper esophageal sphincter and pharyngeal region, often contribute to the development and exacerbation of swallowing issues in those with SCI [29].

Technological risk factors include the use of a tracheostomy and mechanical ventilation. The utilization of a tracheostomy tube may have a disruptive presence on motor and sensory functioning caused by glottis injury, loss of protective reflexes, fixation of the trachea to the anterior neck skin, and esophageal obstruction due to the cuff's contact with the esophagus and hypopharynx [11]. While these devices are believed to assist in preventing aspiration of secretions, Chaw et al. [15], argue that this is not an absolute; aspiration can still occur due to leakage of secretions around the cuff with the size and type of cuff determining this risk depending on how well the tube is sealed. Secretions may be managed through ventilation techniques such as high frequency percussive ventilation which provides low pressure and high frequency ventilations with a high velocity inflow, and mechanical insufflation-exsufflation which gradually applies positive 
pressure to the airway followed by rapid negative pressure to produce secretions [30]. Confirming a causal relationship between dysphagia and ventilator dependence and/or tracheostomy is difficult due to the latter link with pneumonia $[15,30]$.

A remark should be noted about potential differences in the severity of cervical SCI between studies from the United States and those from other parts of the world in terms of trauma etiology. From our findings, American patients were younger, and gunshot wounds and motor vehicle accidents were a common cause of injury. While for non-American studies, a central cord syndrome may have resulted from a fall or other less severe forms of trauma. As such these two populations may differ in their level of impairment.

The findings of this study have important clinical implications. The risk factors identified for the SCI population are different than those in other neurological populations. For example, among individuals with stroke, the development of dysphagia has been correlated with Glasgow Coma Scale score, hemorrhagic volume, presence of intraventricular hemorrhage, and Mini Mental State Examination score [31], as well as National Institutes of Health Stroke Scale score, pontine infarction, and white matter hyperintensities [32]. Our findings may also assist with appropriate treatment planning for the medical management of tetraplegia, specifically regarding interventions which contribute to the risk of developing dysphagia [33, 34]. As dysphagia is associated with several harmful secondary pulmonary complications [11], and significant morbidity [1, $15,34]$, early identification of at-risk individuals is important for the prevention or reduction of these outcomes. Clinicians caring for individuals with SCI should prioritize early screening so that modified diets and oral care or in rare cases extra-oral tube feeding can be instituted. This work can be supported by speech-language pathologists who are the professionals providing assessment, treatment, education, and counselling to individuals with dysphagia. A referral to this discipline should be sought in the early period of recovery $[33,34]$. Timely and effective management of dysphagia can allow these individuals to resume normal diets earlier so that issues of nutritional status are not compromised, and quality of life is preserved.

The current study findings are limited by the inclusion criteria. It is possible that other studies are available that could inform the evidence on this topic, including those written in non-English languages. Additionally, not all of the studies reported proportions for their identified significant risk factors, and therefore RRs could not be calculated or pooled through meta-analysis. The findings are also limited by the small number, and heterogeneity, of studies included for analysis. It is recommended that additional large sample studies are performed to determine if the results can be generalized to the cervical SCI population. Future studies should also aim to standardize methods for the diagnosis of dysphagia and investigate treatments for the condition specific to this clinical population.

\section{Conclusions}

The current review examined all studies written in the English language to date which have reported on risk factors for dysphagia in the SCI population. Eleven significant risk factors were identified for which risk percentages were available, and for which RRs were calculated. It is important for clinicians to be aware of these risk factors when screening patients for dysphagia in all settings to promote optimal care.

Acknowledgements The author team would like to acknowledge the SCIRE project team for being a resource for us to use when conceiving and writing the manuscript (https://scireproject.com).

Author contributions JI conceived the manuscript idea, performed the literature search, article selection, wrote the methods and results, created all figures and tables, and edited and revised the final manuscript for submission. AM assisted in article selection and wrote the discussion section of the manuscript. MM assisted in article selection, wrote the introduction section of the manuscript, and edited all figures and tables. PW provided clinical expertise about the rehabilitation of dysphagia from the perspective of a speech-language pathologist in the introduction and discussion of the manuscript. EL provided clinical expertise about spinal cord injuries in various sections of the manuscript. RT provided clinical expertise about spinal cord injuries in various sections of the manuscript.

\section{Compliance with ethical standards}

Conflict of interest The authors declare that they have no conflict of interest.

\section{References}

1. Wolf C, Meiners TH. Dysphagia in patients with acute cervical spinal cord injury. Spinal Cord. 2003;41:347-53.

2. Castell DO, Donner MW. Evaluation of dysphagia: a careful history is crucial. Dysphagia. 1987;2:65-71.

3. Papadopoulou S, Exarchakos G, Beris A, Ploumis A. Dysphagia associated with cervical spine and postural disorders. Dysphagia. 2013;28:469-80.

4. Logemann JA. Evaluation and treatment of swallowing disorders. Austin, TX: PRO-ED; 1993.

5. Logemann JA, Larsen K. Oropharyngeal dysphagia: pathophysiology and diagnosis for the anniversary issue of diseases of the esophagus. Dis Esophagus. 2012;25:299-304.

6. Jean A. Brain stem control of swallowing: neuronal network and cellular mechanisms. Physiol Rev. 2001;81:929-69.

7. Ertekin C, Aydogdu I. Neurophysiology of swallowing. Clin Neurophysiol. 2003;114:2226-44.

8. Matsuo K, Palmer JB. Anatomy and physiology of feeding and swallowing: normal and abnormal. Phys Med Rehabil Clin N Am. 2008;19:691-707. 
9. Shapiro J. Evaluation and treatment of swallowing disorders. Compr Ther. 2000;26:203-9.

10. Abel R, Ruf S, Spahn B. Cervical spinal cord injury and deglutition disorders. Dysphagia. 2004;19:87-94.

11. Kirshblum S, Johnston MV, Brown J, O’Connor KC, Jarosz P. Predictors of dysphagia after spinal cord injury. Arch Phys Med Rehabil. 1999;80:1101-5.

12. Shem K, Castillo K, Wong S, Chang J. Dysphagia in individuals with tetraplegia: incidence and risk factors. J Spinal Cord Med. 2011;34:85-92.

13. Shem K, Castillo K, Wong S, Chang J, Kolakowsky-Hayner S. Dysphagia and respiratory care in individuals with tetraplegia: incidence, associated factors, and preventable complications. Top Spinal Cord Inj Rehabil. 2012;18:15-22.

14. Consortium for Spinal Cord Medicine. Early acute management in adults with spinal cord injury: a clinical practice guideline for health-care professionals. J Spinal Cord Med. 2008;31:403-79.

15. Chaw E, Shem K, Castillo K, Wong SL, Chang J. Dysphagia and associated respiratory considerations in cervical spinal cord injury. Top Spinal Cord Inj Rehabil. 2012;18:291-9.

16. Berney S, Bragge P, Granger C, Opdam H, Denehy L. The acute respiratory management of cervical spinal cord injury in the first 6 weeks after injury: a systematic review. Spinal Cord. 2011;49:17-29.

17. Moher D, Liberati A, Tetzlaff J, Altman DG. Preferred reporting items for systematic reviews and meta-analyses: the PRISMA statement. PLoS Med. 2009;6:e1000097.

18. Zeng X, Zhang Y, Kwong JS, Zhang C, Li S, Sun F, et al. The methodological quality assessment tools for preclinical and clinical studies, systematic review and meta-analysis, and clinical practice guideline: a systematic review. J Evid-Based Med. 2015;8:2-10.

19. Higgins JP, Thompson SG. Quantifying heterogeneity in a metaanalysis. Stat Med. 2002;21:1539-58.

20. Ihalainen T, Rinta-Kiikka I, Luoto TM, Thesleff T, Helminen M, Korpijaakko-Huuhka AM, et al. Risk factors for laryngeal penetration-aspiration in patients with acute traumatic cervical spinal cord injury. Spine J. 2018;18:81-7.

21. Hayashi T, Sakai H, Maeda T, Ueta T, Shiba K. Risk factors for severe dysphagia in acute cervical spinal cord injury. Spinal Cord. 2017;55:940-3.
22. Shin JC, Yoo JH, Lee YS, Goo HR, Kim DH. Dysphagia in cervical spinal cord injury. Spinal Cord. 2011;49:1008-13.

23. Shem K, Castillo K, Naran B. Factors associated with dysphagia in individuals with high tetraplegia. Top Spinal Cord Inj Rehabil. 2005;10:8-18.

24. Brady S, Miserendino R, Statkus D, Springer T, Hakel M, Stambolis V. Predictors to dysphagia and recovery after cervical spinal cord injury during acute rehabilitation. J Appl Res. 2004;4:1-11.

25. Seidl RO, Nusser-Müller-Busch R, Kurzweil M, Niedeggen A. Dysphagia in acute tetraplegics: a retrospective study. Spinal Cord. 2010;48:197-201.

26. Martino R, Foley N, Bhogal S, Diamant N, Speechley M, Teasell R. Dysphagia after stroke: incidence, diagnosis, and pulmonary complications. Stroke. 2005;36:2756-63.

27. Maeda T, Ueta T, Mori E, Yugue I, Kawano O, Takao T, et al. Soft-tissue damage and segmental instability in adult patients with cervical spinal cord injury without major bone injury. Spine. 2012;37:E1560-6.

28. Momosaki R, Kinoshita S, Kakuda W, Yamada N, Abo M. Noninvasive brain stimulation for dysphagia after acquired brain injury: a systematic review. J Med Invest. 2016;63:153-8.

29. Achem SR, Devault KR. Dysphagia in aging. J Clin Gastroenterol. 2005;39:357-71.

30. Wong S, Shem K, Crew J. Specialized respiratory management for acute cervical spinal cord injury: a retrospective analysis. Top Spinal Cord Inj Rehabil. 2012;18:283-90.

31. Rhie SH, Choi JW, Jeon SJ, Kang SD, Joo MC, Kim MS. Characteristics of patients with aneurysmal subarachnoid hemorrhage and risk factors related to dysphagia. Ann Rehabil Med. 2016;40:1024-32.

32. Fandler S, Gattringer T, Eppinger S, Doppelhofer K, Pinter D, Niederkorn K, et al. Frequency and predictors of dysphagia in patients with recent small subcortical infarcts. Stroke. 2017;48:213-5.

33. Logemann JA. The role of the speech language pathologist in the management of dysphagia. Otolaryngol Clin North Am. 1988;21:783-8.

34. Miller RM, Groher ME. Speech-language pathology and dysphagia: a brief historical perspective. Dysphagia. 1993;8: $180-4$. 